\title{
Notoginsenoside R1 Protects HUVEC Against Oxidized Low Density Lipoproteir (Ox-LDL)-Induced Atherogenic Respr ase via Down-Regulating miR-132
}

\author{
Changgeng Fu ${ }^{a}$ Dexin Yin ${ }^{a}$ Haiying Nie Dajun Sun $^{\mathrm{a}}$ \\ aDepartment of Vascular Surgery, China-Japan Union Hospital of Jilin Universl,
}

Key Words
Atherosclerosis $\bullet$ Ox-LDL $\bullet$ Notoginsenoside R1

\section{Abstract}

Background/Aims: Radix notoginseng is a wel. traditional Chinese herbal medicine, has extensively pharmacological activi carurovascular system. Notoginsenoside R1 (NGR1) is one main active ingredient o the purpose of this study was to evaluate the functional effects $M R$ rosclerosis (AS). Methods: Human umbilical vascular endothelial cells (HUV, vere suvjected to oxidized low density lipoprotein (oxLDL), before which cells were prec ned with NGR1. Cell Counting Kit-8 (CCK-8) assay, flow cytometry, Transwell quarmative real-time polymerase chain reaction (qRT-PCR) and Western blot were fied to assess the impacts of ox-LDL and NGR1 on HUVECs. Besides, the expression nicr.NA-132 (miR-132), and the regulatory role of miR-132 in Matrix Gla Protein D) t., ssion were measured by qRT-PCR and Western blot. Results: NGR1 pre-cond 'ni syented ox-LDL-induced apoptosis, migration and overproduction of Monocyte - h $-m$ tt vant Protein 1 (MCP-1) and Intercellular Adhesion Molecule 1 (ICAM1). miR-12? vas gulated in response to ox-LDL while was down-regulated by NGR1 pre condi ng. The protective actions of NGR1 in ox-LDL-treated HUVECs were enhanced by 132 Jitor, while were attenuated by miR-132 mimic. Besides, the up-regulated mi. i-adi factor. Furthermore, ox-LDL-induced the activation of c-Jun N-terminal Kinase (J) 4) and Nuclear Factor Kappa B (NF-kB) pathways were partially attenuated by NGR1, and en ully eliminated by NGR1 treatment together with MGP overexpression. Conclusion: 1 prevents ox-LDL-induced apoptosis, migration and adhesion-related molecule release In HUVECs possibly via down-regulating miR-132, and subsequent up-regulating MGP.

C. Fu and D. Yin contributed equally to this work.

\begin{tabular}{ll}
\hline Dajun Sun & Department of Vascular Surgery, China-Japan Union Hospital of Jilin University \\
& No.126, Xiantai Street, Changchun 130033, Jilin (China) \\
& E-Mail sundajun0056@sina.com
\end{tabular}




\section{Cellular Physiology Cell Physiol Biochem 2018;51:1739-1750 and Biochemistry Published on/me: 307November $2018 \begin{aligned} & \text { (c) } 2018 \text { The Author(s). Published by S. Karger AG, Basel } \\ & \text { www.karger.com/cpb }\end{aligned}$ \\ Fu et al.: Anti-Atherosclerotic Effect of Notoginsenoside R1}

\section{Introduction}

Atherosclerosis (AS) is the primary pathological base of coronary heart disease, cerebrovascular disease, thromboembolic disease and peripheral artery disease. It is a common disease which is severely harmful to human health, particularly to the elders' health globally [1]. The pathogenesis of AS is complicated and remains unclear. Two theories hay been widely-accepted as the initial events involved in the formation of AS, i.e., "responst to-injury" and "chronic inflammation" $[2,3]$. Recently, a growing number of studies have focused on investigating the role of oxidized low density lipoprotein (ox-LDL) in AS, in 0 to expand the understanding of AS pathogenesis. Formation of ox-LDL is an early and step in the development of AS [4], and ox-LDL has been considered as a key bir arke1 AS diagnosis [5]. ox-LDL takes part in AS through various mechanisms, for example, effects on human umbilical vascular endothelial cells (HUVECs) [6]. Based nes sons, several literatures have applied ox-LDL as a stimuli for establishing an in moa of AS $[7,8]$.

Radix notoginseng is a traditional Chinese herbal medicine $\mathrm{p}$ red frun roots of Panax notoginseng [9]. It has been used for thousands of years in Ch. $r$ hemostasis [9]. Nowadays, a growing number of literatures have focused o harmacological activities of Radix notoginseng on the cardiovascular sys $1 \rightarrow$ Danax notoginseng saponins (PNS) are the main active ingredients of Radix notc s. with the development of pharmacology, a variety of monomer saponins have been id ied, including ginsenoside $\mathrm{Rb} 1$, ginsenoside Rg1 and notoginsenoside R1 GR1). In re d of AS, a previous study has reported NGR1 as a promising anti-AS agent vodulation of inflammation, oxidative stress, lipid metabolism and the expression of at 13]. However, the detailed function of NGR1 on AS, and the possibly underlying $\mathrm{m}$ nis still need to be revealed.

To this end, ox-LDL was used in this alde HUVECs, before which HUVECs were preconditioned with NGR1. Via at apoptosis, migration and the expression of adhesion-related molecules were ass $\quad$ t ee the effects of NGR1 on ox-LDL-treated HUVECs. In addition, we inves 1 atory role of NGR1 in the expression of miR132, in order to decode the un ng mechanisms of the action. Furthermore, Matrix Gla Protein (MGP), an inhibitor of vess 132 in the present work reason ror why we choose miR-132, but not other miRNAs is that: miR-132 has been orte s a highly expressed miRNA in atherosclerotic lesions in ApoE-/- mice [15]. Besi 1 could slightly decrease miR-132 expression in ApoE-/mice [13]. The fir of tms study will further suggest NGR1 as a promising agent for the prevention and 8 a

HUh were purchased from ATCC (Manassas, VA). The cells were routinely cultured in RPMI-1640 (r) aly (Gibco, Grand Island, NY) with $10 \%$ fetal bovine serum (FBS, Gibco), $30 \mu \mathrm{g} / \mathrm{ml}$ endothelial cell ,ror supplement (Collaborative Research, Lexington, MA), and $0.1 \mathrm{mg} / \mathrm{ml}$ heparin (Gibco) at $37^{\circ} \mathrm{C}$ in $5 \%$ HUVECs under passage 7 were used throughout the study.

ox-LDL was prepared by AngYuBio (Shanghai, China). For the establishment of in vitro model of AS, HUVECs were treated by $100 \mathrm{mg} / \mathrm{l}$ of ox-LDL for $24 \mathrm{~h}$.

NGR1 (HPLC $\geqslant 98 \%$ ) purchased from Linyi azeroth biotechnology CO. LTD. (Linyi, China) was dissolved in DMSO (Sigma, St. Louis, MO), and was diluted with the culture medium so that the final concentration of DMSO was less than $0.1 \%$. HUVECs were treated by various doses of NGR1 for $24 \mathrm{~h}$ before ox-LDL treatment. The cells received treatment of $0.1 \%$ DMSO were considered as a blank control. 


\section{Cellular Physiology Cell Physiol Biochem 2018;51:1739-1750 \begin{tabular}{l|l|l|l|l}
\hline DOI: 10.1159/000495677 & 2018 The Author(s). Published by S. Karger AG, Basel \\
and Biochemistry
\end{tabular}

\section{Assessment of cell viability}

HUVECs in 96-well plates ( $5 \times 10^{3}$ cells per well) were treated by NGR1 and/or ox-LDL, after which the culture medium was removed. The cells were washed twice with phosphate buffer saline (PBS, Beyotime, Shanghai, China), and then $10 \mu \mathrm{l} \mathrm{CCK-8} \mathrm{solution} \mathrm{(Dojindo} \mathrm{Molecular} \mathrm{Technologies,} \mathrm{Kyushu,} \mathrm{Japan)} \mathrm{was} \mathrm{added}$ into each well. The plates were incubated at $37^{\circ} \mathrm{C}$ for $2 \mathrm{~h}$, then the absorbance of each well was detected by an ELISA reader (Bio-Rad, Hercules, CA) at $450 \mathrm{nM}$.

\section{Assessment of apoptosis}

After the treatment of NGR1 and ox-LDL, HUVECs in 6-well plates $\left(5 \times 10^{5}\right.$ cells per well) collected by $0.25 \%$ trypsin (Gibico). Apoptosis was measured by the Annexin V-FITC Apoptosis D Kit (Beyotime). At least $1 \times 10^{5}$ cells of each sample were resuspended in $100 \mu \mathrm{l}$ Binding $10 \mu \mathrm{l}$ Annexin V-FITC. After $30 \mathrm{~min}$ of incubation over ice in the dark, $5 \mu \mathrm{l}$ PI and $400 \mu \mathrm{l}$ ice added. The samples were then analyzed by a flow cytometer (Beckman Coulter, San positive and PI-negative cells were considered as apoptotic cells.

\section{Migration assay}

HUVECs $\left(5 \times 10^{4}\right)$ in $200 \mu \mathrm{l}$ non-serum medium were placed in the uppe. mber of the 24-well Transwell plate (8- $\mu \mathrm{m}$ pore insert, Costar-Corning, New York). The $600 \mu \mathrm{l}$ complete medium. After treating with NGR1 and/or ox-LDL, th Is ved with crystal violet and were counted microscopically. In order to rule out the impacts a raton on the calculation of migratory rate, relative migration was calculated as following formul number in lower chamber/ (cell number in lower and upper chambers) $\times 100 \%$. F fields of visio vere randomly selected for the calculation of the relative migration.

\section{Cell transfection}

The mimic, inhibitor and scrambled contro for human miR-132 were purchased from GenePharma (Shanghai, China). Full-length (Invitrogen, Carlsbad, CA) to form a MGP ex on tor. The empty pc-DNA3.1 plasmid was used a a blank control. For MGP silencing, st Gec Ge synthetized by RiboBio (Guangzhou, China) was constructed into pGPU6/Neo plasm ePharma). pGPU6/Neo plasmid with non-targeting sequences was transfected as a blank control, All ctions were conducted in 6-well plates with non-serum medium by using Lipofectam; 00 (Jnvitrogen). At $48 \mathrm{~h}$ of transfection, cells were collected.

Quantitative real-time $p$ chain reaction ( $q R T-P C R$ )

Total RNA in $\mathrm{H}$ as tacracted by using Trizol reagent (Life Technologies Corporation, Carlsbad, CA). For detectio ff xpression, reverse transcription was performed by PrimeScript Reverse Transcriptase akar bal n, China). qRT-PCR was conducted by Taqman Universal Master Mix II (Applied Biosystem ter CAs a . For detection of the expression of Monocyte Chemoattractant Protein 1 (MCP1), ter ell dhesion Molecule 1 (ICAM-1), and MGP, cDNA was synthetized by Transcriptor First Strand cDl thesis (Roche, Basel, Switzerland). qRT-PCR was performed by FastStart Universal SYBR Green Mas, $\quad$ The internal control for miRNAs was U6, and $\beta$-actin for MCP-1, ICAM-1, and MGP. temperature, and then probed at $4^{\circ} \mathrm{C}$ overnight with primary antibodies: MCP-1 (Cat \# M2MCP1BI, Thermo Fisher Scientific, Waltham, MA), ICAM-1 (Cat \# MA5407, Thermo Fisher Scientific), p53 (Cat \# ab26, Abcam, Cambridge, MA), cleaved caspase-3 (Cat \# ab2302, Abcam), pro caspase-3 (Cat \# ab44976, Abcam), MGP (Cat \# ab192396, Abcam), c-Jun N-terminal Kinase (Jnk) (Cat \# ab199380, Abcam), p-Jnk (Cat \# ab47337, Abcam), c-Jun (Cat\# ab32137, Abcam), p-c-Jun (Cat \# ab32385, Abcam), p65 (Cat \# ab32536, Abcam), p-p65 (Cat \# ab86299, Abcam), IкB $\alpha$ (Cat \# ab7217, Abcam), p-IкB $\alpha$ (Cat \# ab133462, Abcam), and $\beta$-actin (Cat \# 
ab8226, Abcam). Following incubation with the secondary antibodies for $1 \mathrm{~h}$ at room temperature, protein bands were visualized by enhanced chemiluminescence method. Intensity of the bands was analyzed by Image Lab $^{\text {TM }}$ Software (Bio-Rad, Hercules, CA).

\section{Statistics}

Data are presented as mean \pm SD from three independent experiments. Statistical differences betwee two groups were tested by Student $t$ test, and statistical differences between three or more were determine by a one-way analysis of variance (ANOVA). SPSS 19.0 software (SPSS Inc., Chicago, IL) was used in this procedure. $p$-values of $<0.05$ were considered as significant results.

\section{Results}

ox-LDL promotes apoptosis, migration and adhesion-related molecule

HUVECs were subjected to $100 \mathrm{mg} / \mathrm{l}$ ox-LDL for $24 \mathrm{~h}$. As a resu' ct. 'ity was significantly reduced by ox-LDL to $53.87 \%$ (p<0.05, Fig. 1A). Besides ptosis mas induced by ox-LDL. As shown in Fig. 1B-1C, apoptotic cell rate was increased $\quad 2.92 \%$ to $21.02 \%$ $(\mathrm{p}<0.05)$, and the protein expression of p53 was up-regu $\quad$ cas -3 was cleaved remarkably. Fig. 1D showed that the relative migration was increased by ox-LDL treatment $(\mathrm{p}<0.05)$. Further, qRT-PCR and Western blot ana cruperformed to assess the expression changes of adhesion-related molecules. Resu n Fig. 1E-1G showed that, the mRNA and protein levels of MCP-1 and ICA were both only expressed in response to ox-LDL $(\mathrm{p}<0.05)$.

Fig. 1. Effects of oxidized low density lipoprotein (ox-LDL) on HUVECs. (A) Viability, (B) the rate of apoptotic cells, $(C)$ expression of apoptosis-rela proteins, (D) relative migrati (E) mRNA levels of $\mathrm{N}$ ICAM-1, and levels of MCP-1 HUVECs aft $4 \mathrm{ho}$ sure

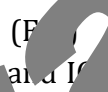
co ito th atrol group.
(B)

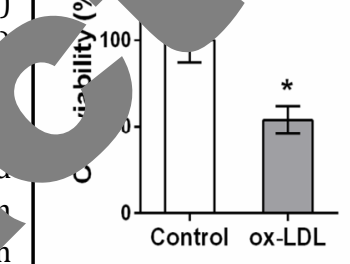

D

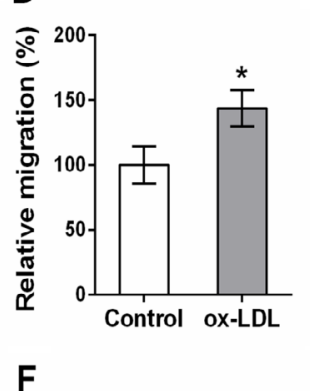

$\mathbf{F}$

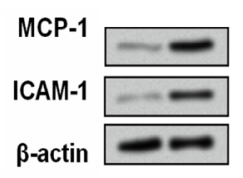

Control ox-LDL

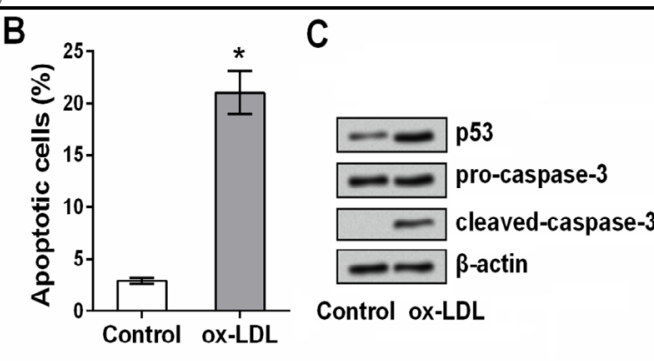

E

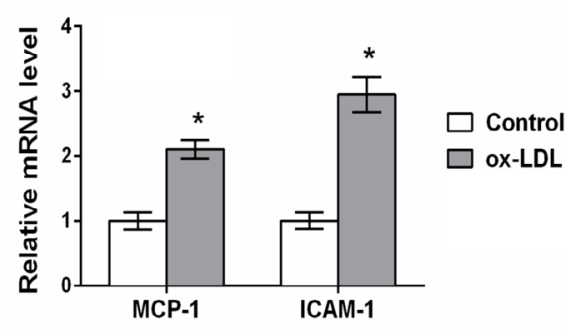

G

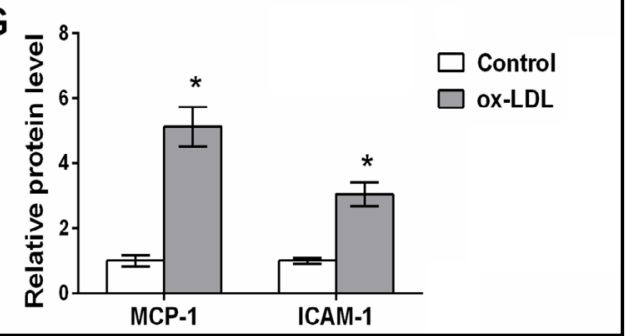


Fig. 2. Effects of notoginsenoside R1 (NGR1) on oxidized low density lipoprotein (ox-LDL)injured HUVECs. (A) Viability of HUVECs treated by various doses of NGR1 for 24 h. * $\mathrm{p}<0.05$ compared to the group without NGR1 treatment. (B) The rate of apoptotic cells, (C) expression of apoptosis-related proteins, (D) relative migration, (E) mRNA and (F) protein levels of MCP1 and ICAM-1, in HUVECs after pre-conditioning with $30 \mu \mathrm{M}$ NGR1 for $24 \mathrm{~h}$, and subsequent exposure of $100 \mathrm{mg} / \mathrm{l}$ ox-LDL for 24 h. $*$ p $<0.05$ compared to the indicated group.

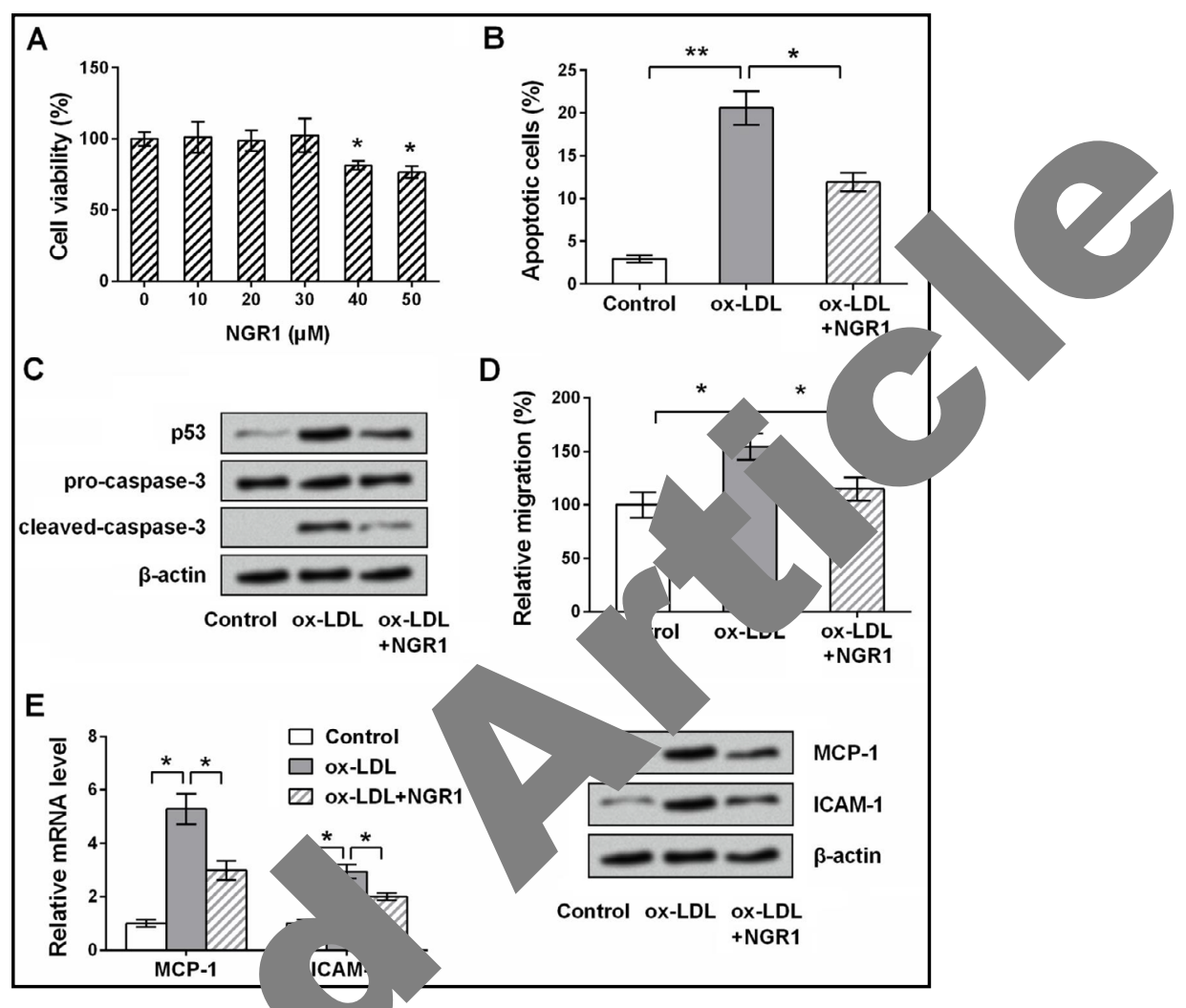

Fig. 3. Effects of notoginsenoside R1 (NGR1 on miRNA expression. RNA levels of miR-1 miR-29b and miR-146a in HUVEC. conditioning with $30 \mu \mathrm{M}$ NGR1 for subsequent exposure of $100 \mathrm{mg} / \mathrm{l} \mathrm{ox}-\mathrm{L}$ 24 h. $^{*} \mathrm{p}<0.05$ compared to the
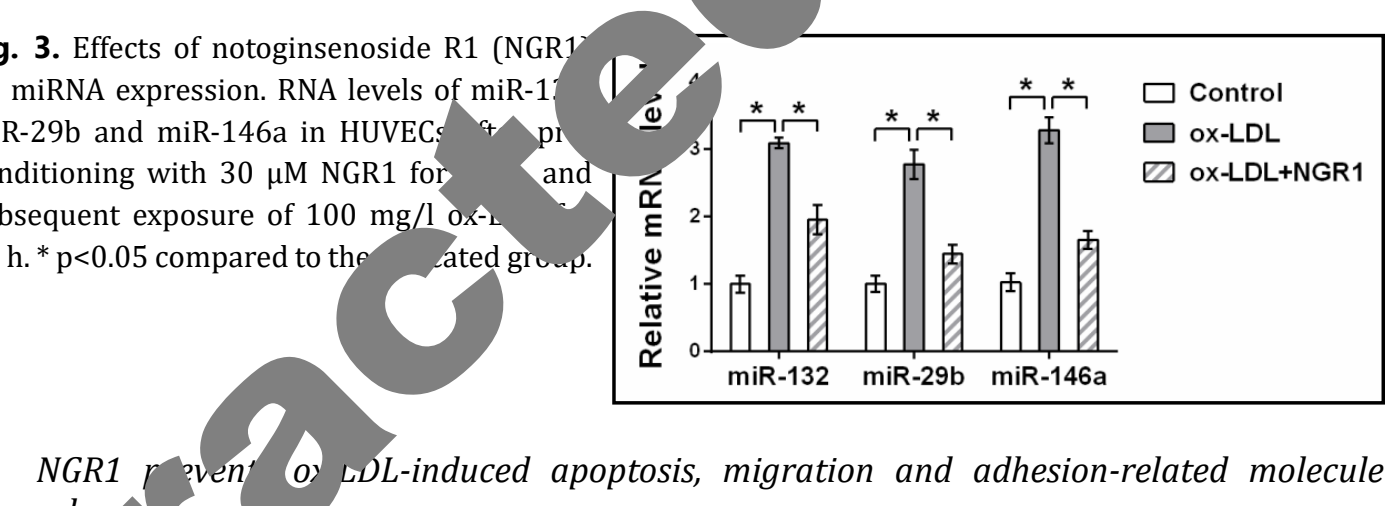
miR-132 miR-29b miR-146a relea in on of ility was observed at 40 and $50 \mu \mathrm{M}$ doses of NGR1 (p<0.05, Fig. 2A). $30 \mu \mathrm{M}$ was $t^{-d}$ as a NGR1-treating condition for use in the following experiments. HUVECs in $A$ treated by NGR1 and ox-LDL, and we found that the apoptosis induced by ox(1) $\triangle$ yas attenuated by NGR1 pre-conditioning $(\mathrm{p}<0.05$, Fig. $2 \mathrm{~B}-2 \mathrm{C})$. In addition, the impacts 10 LDL on HUVECs migration and MCP-1 and ICAM-1 expression were attenuated when ECs were pre-conditioned with NGR1 (ox-LDL group vs. ox-LDL + NGR1 group, p<0.05,

Fig. 2D-2F).

NGR1 inhibits the expression of miR-132, miR-29b and miR-146a

miR-132, miR-29b and miR-146a are three pro-inflammatory miRNAs, which can be upregulated by ox-LDL or ApoE knockout [15-17]. The present work studied the expression changes of these miRNAs, in order to reveal whether NGR1 functioned to HUVECs via a miRNA-dependent pathway. By performing qRT-PCR, we found that miR-132, miR-29b and 
miR-146a were all significantly up-regulated in ox-LDL-treated cell $(\mathrm{p}<0.05)$, and the upregulations induced by ox-LDL were partially eliminated by NGR1 preconditioning $(\mathrm{p}<0.05$, Fig. 3). miR-132 was selected for the follow-up experiments.

NGR1 prevents ox-LDL-induced atherogenic response through down-regulation of miR132

The specific mimic and inhibitor for miR-132 was transfected into HUVECs respectively, to see the involvement of miR-132 in the pharmacological activities of NGR1. As shown in Fig. $4 \mathrm{~A}$, compared to the NC group, the expression of miR-132 was significantly overexpre by mimic transfection, while was significantly suppressed by inhibitor transfection oth $\mathrm{p}<0.05)$. The inhibition of apoptosis induced by NGR1 in ox-LDL-treated JVE vas enhanced by miR-132 inhibitor, while was attenuated by miR-132 mimic $(\mathrm{p}<0$ Fis 4C). Also, NGR1-induced migration inhibition, and MCP-1 and ICAM-1 tions were enhanced by miR-132 inhibitor, and were attenuated by miR-132 $\mathrm{m} \quad(\mathrm{p}<0 .$, , Fig. 4D-4F).

MGP is down-regulated by miR-132 mimic

MGP, an inhibitor of vessel [14], has been regarded a treatment target for AS [19]. Thus, the expression changes dysregulation were detected, to evaluate the involvement of $n$ AS. Surprisingly, we found that both the mRNA and protein le

Fig. 4. Effects of miR-132 on notoginsenoside R1 (NGR1)- and oxidized low density lipoprotein (ox-LDL)treated HUVECs. (A) RNA levels of miR132 in HUVECs after transfection with mimic, inhibitor and scrambled control (NC) for miR-132. The rate of apo ic cells, (C) ey essic () of apop ${ }^{+}$relat pro in (1. lative mic $1,(\mathrm{E})$ NA anà $\left(t^{\prime}{ }^{\prime} n\right.$ levels (1) HUVECs were an cted with miRmimic, miR-132 inhibitor or $\mathrm{NC}$, and then were in turn treated by NGR1 and ox-LDL. * $\quad$ p $<0.05$ compared to the indicated group.

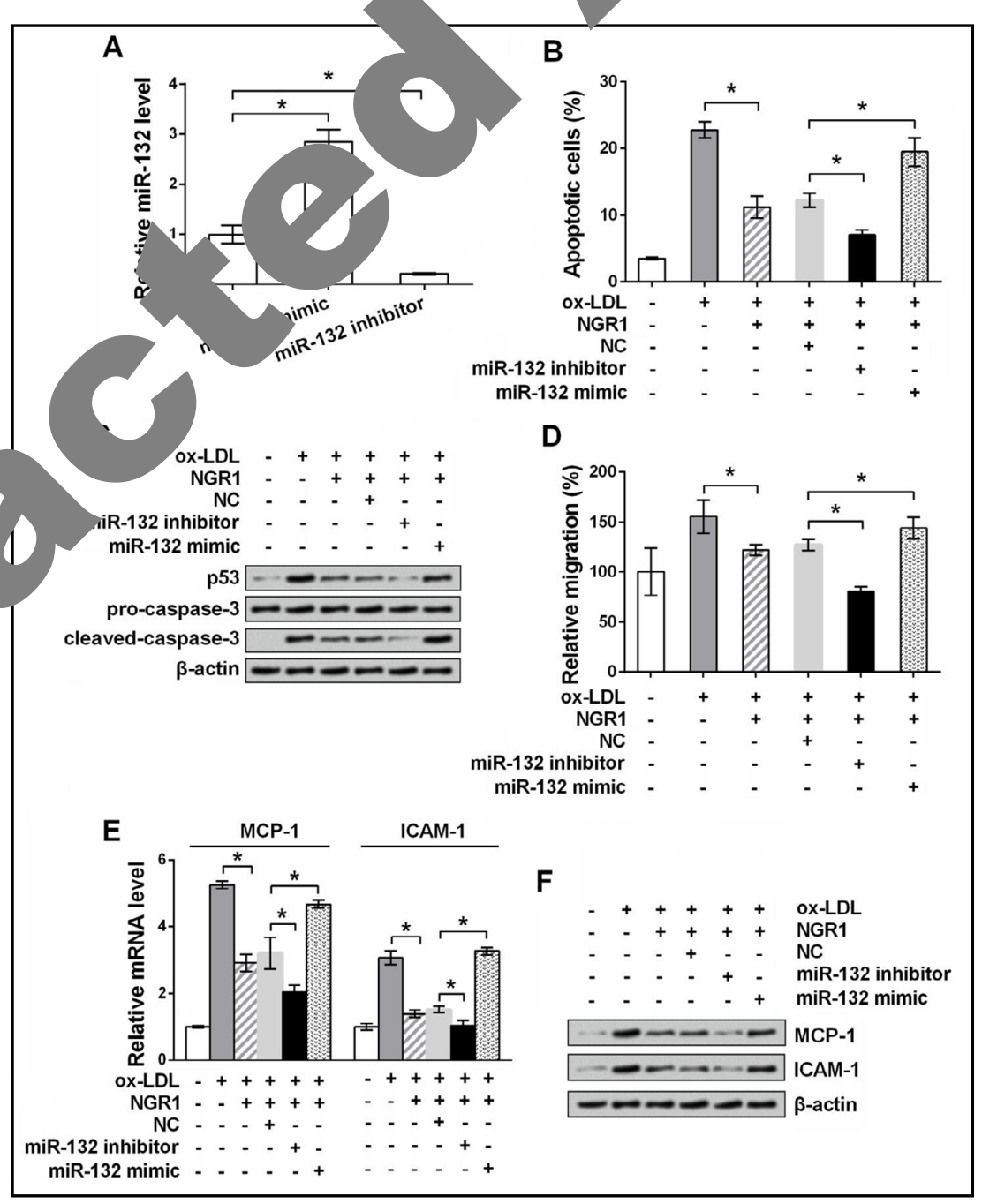


by miR-132 inhibitor transfection, while were down-regulated by mimic transfection $(\mathrm{p}<0.05$, Fig. 5A-5B). Next, in silico analysis was carried out to predict whether MGP was a target gene for miR132. By searching on Targetscan and microRNA. org online databases, no targeting relationship between miR-132 and MGP was found. Thus, we inferred that the relationship between miR-132 and MGP is very complicated that some other factors may be involved.

\section{MGP prevents ox-LDL-induced migration and} adhesion-related molecule release

The expression of MGP in HUVECs was altered by vector or shRNA transfection. As shown in Fig. 6A-6B, pc-MGP transfection significantly elevated MGP expression, and sh-MGP transfection reduced MGP expression $(\mathrm{p}<0.05)$. Then, we found that ox-LDL-induced increases in migration and the expression of MCP-1 and ICAM-1 were attenuated by pc-MGP and were enhanced by sh-MCP $(\mathrm{p}<0.05$,

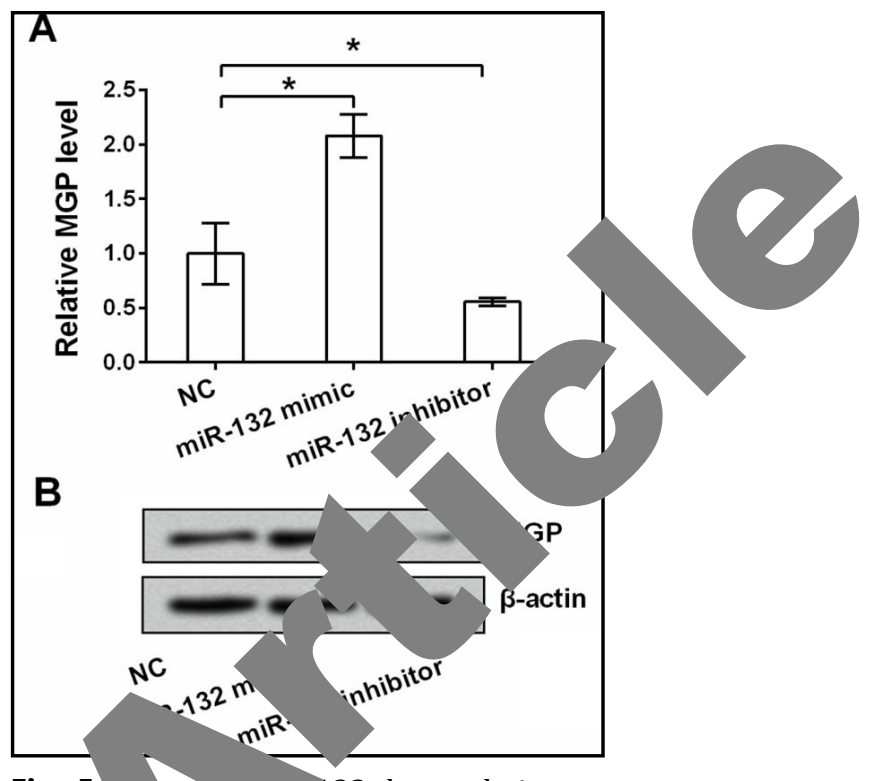

Fig. 5. cts 132 dysregulation on

MGP exp A. (A) mRNA and (B) protein Fig. 6C-6E).

levels of $\mathrm{l}$ in HUVECs after transfection with miR-1 $<$ mimic, miR-132 inhibitor or rambled control (NC). * $\mathrm{p}<0.05$ compared $\bigcirc$ indicated group.

Fig. 6. Effects of MGP dysregulation on oxidized low density lipoprotein (ox-LDL)-treated HUVECs.

(AB) mRNA and protein levels of MGP in HUVECs after transfectior with pc-DNA, p MGP, sh-NC shMGP. (C) tive $\mathrm{mR}$ and (1) of rar ection with DNA, pc-MGP, sh-NC or sh-MGP, and subsequent exposure of ox-LDL. $* \mathrm{p}<0.05$ compared to the indicated group.

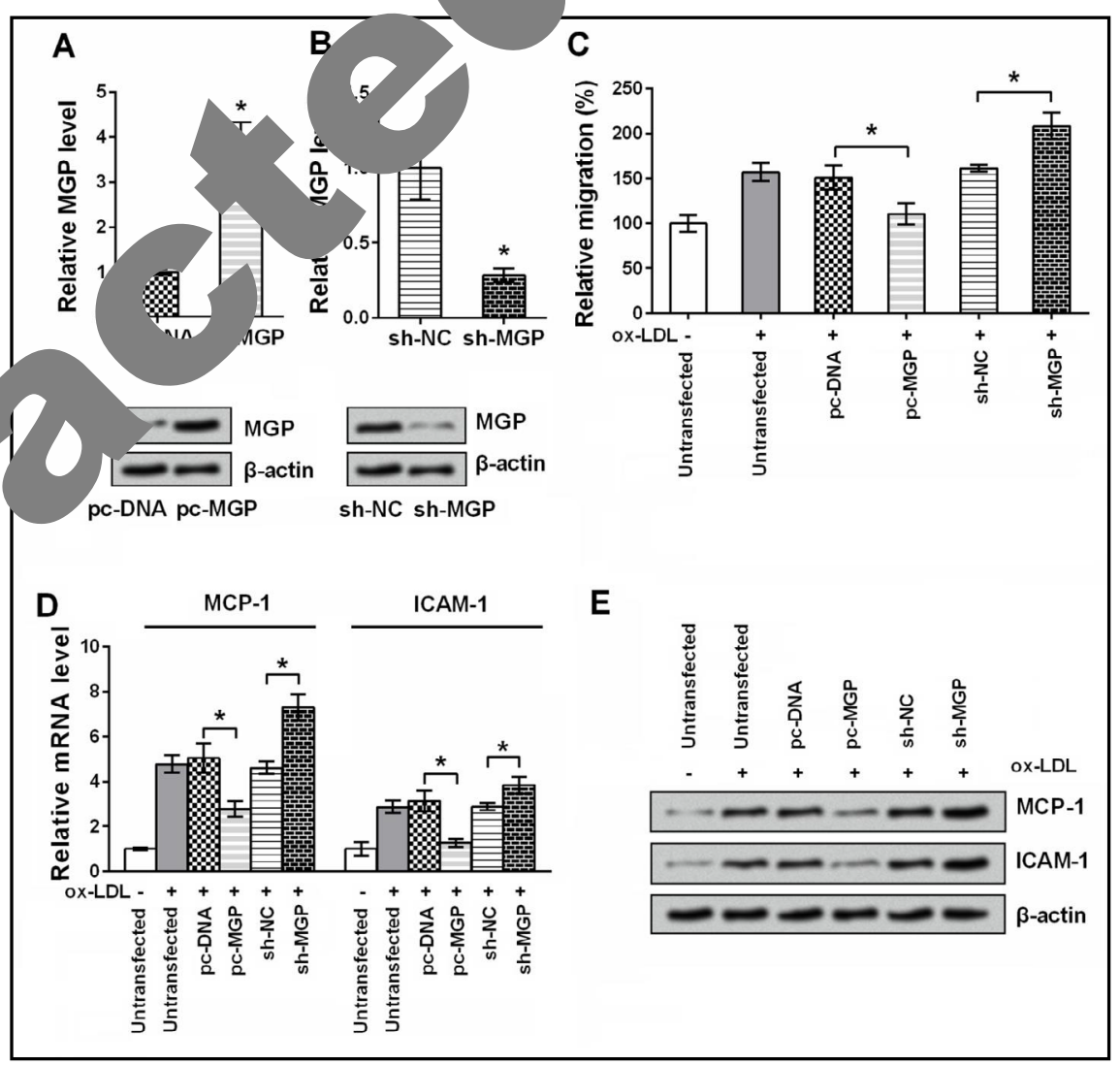




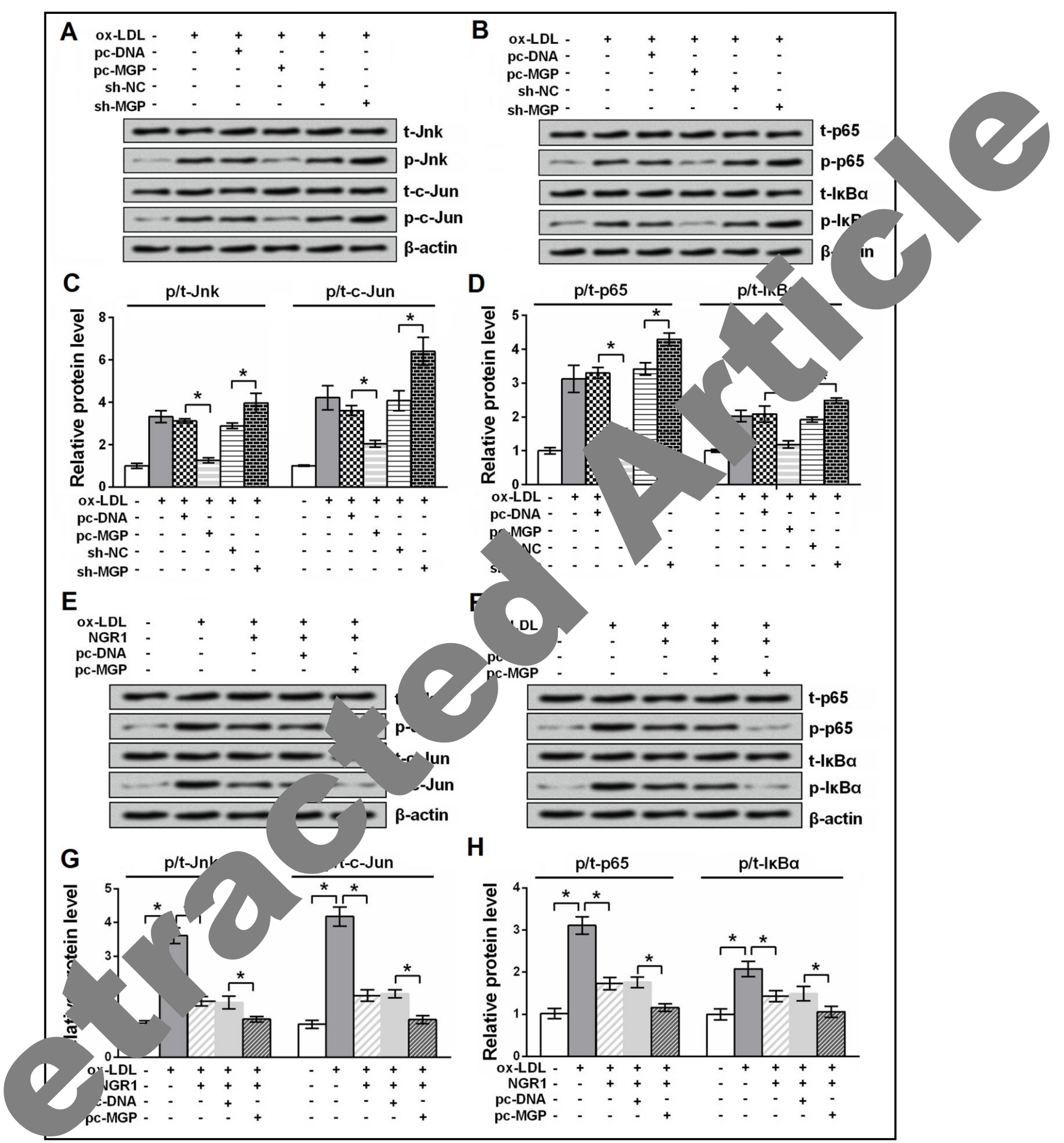

Fig. 7. Effects of notoginsenoside R1 (NGR1) treatment and MGP dysregulation on JNK and NF- $\mathrm{B}$ pathways. $(A, C)$ Protein levels of Jnk, c-Jun, and (B, D) protein levels of p65, I $\mathrm{B} \alpha$ in HUVECs after transfection with pc-DNA, pc-MGP, sh-NC or sh-MGP, and subsequent exposure of ox-LDL. (E, G) Protein levels of Jnk, c-Jun, and $(F, H)$ protein levels of $\mathrm{p} 65, \mathrm{I} \kappa \mathrm{B} \alpha$ in HUVECs after transfection with pc-DNA/pc-MGP, and subsequently treated by NGR1 and ox-LDL. * $\mathrm{p}<0.05$ compared to the indicated group. 


\section{Cellular Physiology Cell Physiol Biochem 2018;51:1739-1750

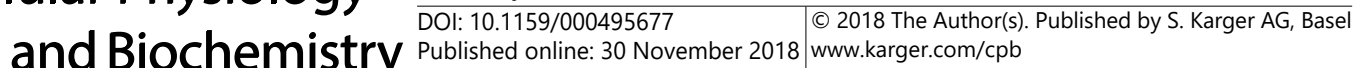

\section{$M G P$ deactivates JNK and NF- $\kappa B$ pathways}

Furthermore, we concerned the regulatory role of MGP in JNK and NF- $\kappa B$ pathways, to reveal the underlying mechanism of which MGP protected HUVECs. We found that oxLDL-induced the activation of JNK and NF- $\kappa B$ pathways, as Jnk, c-Jun, p65 and I $\kappa$ B $\alpha$ were all significantly phosphorylated by ox-LDL treatment ( $<<0.05$, Fig. 7A-7D). More importantly, the activation of these two signaling was blocked by MGP overexpression while w? accelerated by MGP suppression ( $\mathrm{p}<0.05)$. Moreover, the effects of NGR1 treatment togethe. with MGP overexpression on the activation of JNK and NF- $\kappa B$ pathways induced by ox-LDL were tested. As shown in Fig. 7E-7H, the activation of these two signaling induced by ox was attenuated by NGR1 ( $<<0.05)$, however NGR1 together with MGP overexpressior fully eliminate the activation $(\mathrm{p}<0.05)$.

\section{Discussion}

The formation of plaques is a multi-stage and chronic process, in $\mathrm{r}$ events occurring, including vascular endothelial cell damago adhes lymphocytes, invasion into endothelium, foam cell transf fatt, reak formation, and smooth muscle cell migration and hyperplasia. This stu ma used on the effects of NGR1 on HUVECs damage induced by ox-LDL, to prelimin of NGR1 for AS. We found that NGR1 pre-conditioning preven x-LDL-induced apoptosis, migration and the overproduction of MCP-1 ar CAM-1. We ditionally found that miR132 was up-regulated in response to ox-LDL h was down-regulated by NGR1 preconditioning. The up-regulated miR-132 furth ec a the expression of MGP, which in turn repressed the activation of JNK and NF- $\mathrm{KL}$

Vascular endothelial cell damage is AS. High concentration of events of the devent of AS. High concentration of ox-LDL ind $c S$ apoptosis via multiple pathways, including ROS generation, caspase, and alterati 1 a ptosis-related gene expressions [20]. This was also confirmed in this ste at $\delta / 1$ of ox-LDL significantly increased the rate of apoptotic cells, and remar? cleaved caspase-3. Besides, ox-LDL up-regulated the expression of p53, which is ont of apoptosis in malignant cells [21] and AS-related cell types [22]. Although cytotoxic effects of ox-LDL on vascular endothelial cells have been well-established, $\mathrm{t}$ ] xact le of ox-LDL in migratory capacity is still confusing. Sun et al., demonstrated that o. Aibited the migration of HUVECs by performing Transwell assay, without ex the proliferation-inhibitory impacts of ox-LDL on the number of the migrated ce $[\vec{b}$, vever, the opposite effect of ox-LDL has been reported by Bao et al., in the sa cel ne [24]. Consistent with the findings of Bao et al., we suggested that oxLDL pror d HU S migration by ruling out proliferation-inhibitory impact. Moreover, we $r r^{3}$ tio found that ox-LDL increased the release of two adhesion-related molecules (M and 1 -1), further confirmed the migration-promoting role of ox-LDL in HUVECs. MC.- motactic protein for monocytes [25], contributes in monocyte-endothelium sio. d subsequent transendothelial migration [26].

The anti-AS effect of PNS has been sporadically studied. A previous study performed nf $\mathrm{E}$-/- mice demonstrated that, PNS decreased the serum ox-LDL level and the ratio of que area to vessel area [27]. Another investigation showed that PNS protected HUVECs against ox-LDL-induced injury partially via down-regulation of ICAM-1 [28]. However, to our best of knowledge, only one literature has reported the anti-AS effect of NGR1 on an ApoE-/- mice model [13]. Herein, the same conclusion was drawn from the in vitro model made by ox-LDL in HUVECs. Also, the protective effects of NGR1 against ox-LDL-induced inflammation have been mentioned in vascular endothelial cells [29]. All these suggested the potential usage of NGR1 in AS. 


\section{Cellular Physiology Cell Physiol Biochem 2018;51:1739-1750

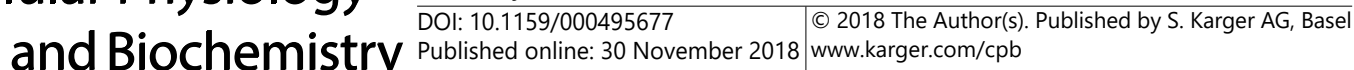 \\ Fu et al.: Anti-Atherosclerotic Effect of Notoginsenoside R1}

It is well-known that AS is an inflammatory disease [3], with expression changes of multiple of miRNAs [30]. Among which, miR-132, miR-29b and miR-146a have been emerged as key regulators in inflammation-mediated processes [31-33]. Besides, previous studies have demonstrated that miR-29b and miR-146a could be up-regulated by ox-LDL, and miR-132 could be up-regulated by ApoE knockout [15-17]. The present work showed that all of these three miRNAs were up-regulated in ox-LDL-treated HUVECs, and were dowr regulated by NGR1 preconditioning. It seems that the effects of NGR1 on miR-132 expression, are nonspecific. The impacts of NGR1 on miRNA expression might be via both genomic (transcriptional) and non-genomic mechanisms of action. Furthermore, we selected 132 for use in the follow-up rescue assays, since miR-132 has been reported to pr TNF- $\alpha$-induced inflammation and cell death of HUVECs [34]. Besides, Kur swar and his colleagues have mentioned that deletion of miR-212/132 cluster increased vasodilatory function [35]. We found that the protective effects of NGP in LDLinduced injury in HUVECs were attenuated by miR-132 mimic. These data ed tha vGR1 functioned to HUVECs possibly via down-regulation of miR-132. How er, are required to verify whether miR-29b and miR-146a are two othe vnstreani effectors of NGR1.

MGP is an important inhibitor of vessel and cartilage ca' ighly expressed in human atherosclerotic plaques [14]. Elevated level of MG St. associated with the increased risk of cardiovascular morbidity and mortality [18 AS work, MGP was found to be up-regulated by miR-132 inhibitor, indicating MGP mig e one of the downstream genes of miR-132. Besides, by searching on Tar? an and mic RNA.org online databases, no targeting relationship between miR-132 and 1 was found. Thus, we inferred that the relationship between miR-132 and MGP is very thed that some other factors may be involved. We additionally found that MGP ove pre wh could help HUVECs to maintain non-migration and non-adhesion in ox-LD dition. Similar findings were reported by Yao et al., that MGP overexpression auv atherosclerotic lesion size and inflammation in ApoE-/- mice [36].

A number of signaling pa $N F-\kappa B$ have been widely-a 3 a relevant to AS [37], among which JNK and N key pathways responsible for AS [38, 39]. Specific inhibition of the activity of JNK and pathways may be effectively therapeutic approach to prevent and/or treat 38,39$]$. In this paper, we showed that ox-LDL-induced the activation of JNK and N $\quad B$ p ways, and NGR1 attenuated the activation of these two signaling. This phenome $s$ in line with previous studies $[29,40]$, indicating NGR1 exerted anti-AS $f$ hrough inhibiting ox-LDL-induced JNK and NF- $\mathrm{KB}$ activation. More interestingly, $N$, 1 r with MGP overexpression could fully eliminate the activation of these two si alin $\mathrm{Tb}$ s, we inferred that NGR1 protected HUVECs against ox-LDL possibly via regul MG , ach subsequently inhibiting JNK and NF- $\kappa$ B pathways.

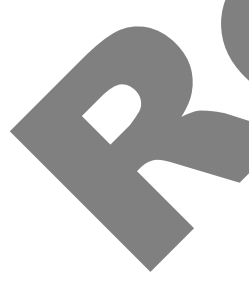

I conclusion, we show here that NGR1 prevents ox-LDL-induced apoptosis, migration

and dhesion-related molecule release in HUVECs. The protective actions of NGR1 may be down-regulation of miR-132, and subsequent up-regulation of MGP. The findings provide in vitro evidence that NGR1 exerted anti-AS effect.

\section{Disclosure Statement}

The authors declare that they have no competing interests. 


\section{Cellular Physiology Cell Physiol Biochem 2018;51:1739-1750

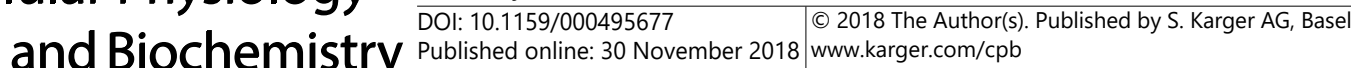 \\ Fu et al.: Anti-Atherosclerotic Effect of Notoginsenoside R1}

\section{References}

1 Collins AR, Lyon CJ, Xia X, Liu JZ, Tangirala RK, Yin F, Boyadjian R, Bikineyeva A, Pratico D, Harrison DG, Hsueh WA: Age-accelerated atherosclerosis correlates with failure to upregulate antioxidant genes. Circ Res 2009;104:e42-54.

2 Ross R: The pathogenesis of atherosclerosis--an update. N Engl J Med 1986;314:488-500.

- 3 Libby P, Ridker PM, Maseri A: Inflammation and atherosclerosis. Circulation 2002;105:1135-1143.

-4 Bergmark C, Wu R, de Faire U, Lefvert AK, Swedenborg J: Patients with early-onset peripheral vascular disease have increased levels of autoantibodies against oxidized LDL. Arterioscler Thromb Vasc Biol 1995;15:441-445.

-5 Maggi E, Finardi G, Poli M, Bollati P, Filipponi M, Stefano PL, Paolini G, Grossi A, Clot P, Alb of autoantibodies against oxidized LDL as an additional marker for atherosclerotic risk. Corc 1993;4:1119-1122.

6 Claise C, Chalas J, Edeas M, Abella A, Khalfoun Y, Laurent D, Lindenbaum A: Comparis density lipoprotein toxicity on EA.hy 926 cells and human vein endothelial cells: ir enc
systems. Cell Mol Life Sci 1997;53:156-161.

7 Qi JC, Liu PG, Wang C, Zheng AD, Wan Z: Tacrolimus protects vascular ondothelià from injuries caused by Ox-LDL by regulating endoplasmic reticulum stress. Eur Rev M $\quad ; 21: 3966-3973$. Liu J, Yao S, Wang S, Jiao P, Song G, Yu Y, Zhu P, Qin S: D-4F, an apolip protects human umbilical vein endothelial cells from oxidized low-de preventing the downregulation of pigment epithelium-derived factor 2014;63:553-561.

-9 Yang X, Xiong X, Wang H, Wang J: Protective effects of $\mathrm{p}_{\mathrm{c}}$ diseases: a comprehensive overview of experimenta 2014;2014:204840.

10 Li W, Li X, Du Q Li F, Zhu Y, Liu Y, Ma J, Wan L Thà ect of tongluojiunao injection made from sanqi (Radix Notoginseng) and zhizi (Fruc và niae) on brain microvascular endothelial cells and astrocytes in an in vitro ischemic model. J

11 Shang Q, Xu H, Liu Z, Chen K, Liu A Systematic Review of Random 2013;2013:940125.

-12 Yuan Z, Liao Y, Tian G, Li inhibit Zymosan $\mathrm{A}$ indu kappaB translocation. J L Aacol 2011;138:150-155.

13 Jia C, Xiong M, Yi J, Du X, Yang Q, Wang W, Chen Y, Zhang T: Notoginsenoside R1 attenuates atherosclero es oE deficient mouse model. PLoS One 2014;9:e99849.

$>14$ Shanaha $\mathrm{M}, \mathrm{Cz} \mathrm{NF}^{\mathrm{F}}$ Metcalfe JC, Weissberg PL: High expression of genes for calcification-regulating prote huma erosclerotic plaques. J Clin Invest 1994;93:2393-2402.

15 Xjng Cui J, Wang P, Du X, Yang Q, Zhu Y, Wang W, Zhang T, Chen Y: Shexiang Tongxin dropping pill nuates rosclerotic lesions in ApoE deficient mouse model. J Ethnopharmacol 2015;159:84-92.

16 Y Yang YS, Hu CY, Chang WC, Liao YC, Dai CY, Juo SH: OxLDL up-regulates microRNA-29b, leading to epig ac modifications of MMP-2/MMP-9 genes: a novel mechanism for cardiovascular diseases. Faseb j 2) 11;25:1718-1728.

Z, Wang S, Zhao W, Sun Z, Yan H, Zhu J: Oxidized low-density lipoprotein upregulates microRNA-146a via JNK and NF-kappaB signaling. Mol Med Rep 2016;13:1709-1716.

Buyukterzi Z, Can U, Alpaydin S, Guzelant A, Karaarslan S, Mustu M, Kocyigit D, Gurses KM: Enhanced serum levels of matrix Gla protein and bone morphogenetic protein in acute coronary syndrome patients. J Clin Lab Anal 2017;23:10.1002/jcla.22278.

19 Mayer 0, Jr.: Matrix Gla protein as natural inhibitor of vascular calcification and potential treatment target. Cas Lek Cesk 2016;155:13-16.

-20 Salvayre R, Auge N, Benoist H, Negre-Salvayre A: Oxidized low-density lipoprotein-induced apoptosis. Biochim Biophys Acta 2002;1585:213-221.

21 Aubrey BJ, Kelly GL, Janic A, Herold MJ, Strasser A: How does p53 induce apoptosis and how does this relate to p53-mediated tumour suppression? Cell Death Differ 2018;25:104-113. 


\section{Cellular Physiology Cell Physiol Biochem 2018;51:1739-1750 and Biochemistry DOl: 10.1159/000495677 2010 (0) 2018 The Author(s). Published by S. Karger AG, Basel

-22 Mercer J, Mahmoudi M, Bennett M: DNA damage, p53, apoptosis and vascular disease. Mutat Res 2007;621:75-86.

-23 Sun H, Zhu X, Zhou Y, Cai W, Qiu L: C1q/TNF-Related Protein-9 Ameliorates Ox-LDL-Induced Endothelial Dysfunction via PGC-1alpha/AMPK-Mediated Antioxidant Enzyme Induction. Int J Mol Sci 2017;18:1097.

24 Bao MH, Li GY, Huang XS, Tang L, Dong LP, Li JM: Long non-coding RNA LINC00657 acting as miR-5903p sponge to facilitate low concentration oxidized low-density lipoprotein-induced angiogenesis. Mol Pharmacol 2018;93:368-375.

25 Randolph GJ, Furie MB: A soluble gradient of endogenous monocyte chemoattractant protein-1 promotes the transendothelial migration of monocytes in vitro. J Immunol 1995;155:3610-3618.

-26 Takahashi M, Masuyama J, Ikeda U, Kitagawa S, Kasahara T, Saito M, Kano S, Shimada K: Suppressive endogenous endothelial monocyte chemoattractant protein-1 on monocyte transendothe vitro. Arterioscler Thromb Vasc Biol 1995;15:629-636.

27 Liu G, Wang B, Zhang J, Jiang H, Liu F: Total panax notoginsenosides prevent atherosc in apolipoprotein E-knockout mice: Role of downregulation of CD40 and MMP-9 expr Ethnopharmacol 2009;126:350-354.

-28 Qin JH, Zhu LQ, Cui W: Effects of panax notoginseng saponins on expression of $j$ molecule-1 in human umbilical vein endothelial cells injury induced bv oxidizea Zhongguo Zhong Xi Yi Jie He Za Zhi 2008;28:1096-1099.

-29 Su P, Du S, Li H, Li Z, Xin W, Zhang W: Notoginsenoside R1 inhibits o inflammatory cytokines production in human endothelial EA.hy926

30 Laffont B, Rayner KJ: MicroRNAs in the Pathobiology and Therapy of A 2017;33:313-324.

-31 Marques-Rocha JL, Samblas M, Milagro FI, Bressan J, Mc. inflammation-related diseases. Faseb j 2015;29:359

32 Yuan H, Ma J, Li T, Han X: MiR-29b aggravates lipopc damage by regulation of NF-kappaB and JNK 33 Habibi F, Ghadiri Soufi F, Ghiasi R, Khaman Alv cpour MR: Alteration in Inflammation-related miR146a Expression in NF-KB Signaling Path Dic Rat Hippocampus. Adv Pharm Bull 2016;6:99103.

34 Zhang L, Huang D, Wang Q, Shen and induces pro-inflammatorv nroces_ascular endothelial inflammation through blockade of the SREBP-1c metabolic path ardiovasc Drugs Ther 2014;28:303-311.

-35 Kumarswamy R, Volkme I, Bee nn J, Napp LC, Jabs O, Bhayadia R, Melk A, Ucar A, Chowdhury K, Lorenzen JM, Gupta SK, L um T: Vascular importance of the miR-212/132 cluster. Eur Heart J 2014;35:3224-?

-36 Yao Y, Bennet morphog etic tei protects against atherosclerosis and vascular calcification. Circ Res 2010;107:485494.

37 Honkin. Molecular biology of atherosclerosis. Physiol Rev 2013;93:1317-1542.

38 D, On W, Zapolska-Downar D: Mitogen-activated protein kinases in atherosclerosis. Postepy Hig (Online) 2014;68:10-22. Pate Giaginis C, Tsigris C, Patsouris E, Theocharis S: NF-kappaB signaling at the crossroads of flammation and atherogenesis: searching for new therapeutic links. Expert Opin Ther Targets 014;18:1089-1101. Tu L, Wang Y, Chen D, Xiang P, Shen J, Li Y, Wang S: Protective Effects of Notoginsenoside R1 via Regulation of the PI3K-Akt-mTOR/JNK Pathway in Neonatal Cerebral Hypoxic-Ischemic Brain Injury. Neurochem Res 2018;43:1210-1226. 